\title{
Sustainable small-scale, membrane based arsenic remediation for developing countries
}

\author{
J. Hoinkis ${ }^{1}$, E.E. Cañas Kurz ${ }^{1}$, U. Hellriegel ${ }^{1}$, T.V. Luong ${ }^{2,3}$ \& J. Bundschuh ${ }^{3}$ \\ ${ }^{1}$ Center of Applied Research, Karlsruhe University of Applied Sciences, Karlsruhe, Germany \\ ${ }^{2}$ Vietnamese-German University, Ho Chi Minh City, Vietnam \\ ${ }^{3}$ UNESCO Chair on Groundwater Arsenic within the 2030 Agenda for Sustainable Development \& Faculty of Health, \\ Engineering and Sciences, University of Southern Queensland, Toowoomba, Australia
}

\begin{abstract}
Membrane technologies for small-scale arsenic removal are currently mainly involving nanofiltration, reverse osmosis, membrane distillation and electrodialysis. Their advantages are the simplicity of the technology and the scalability down to very small modules. Forward osmosis is a relatively new technology for arsenic removal which was mainly applied so far on laboratory scale. Basically, all membrane technologies, with the exception of membrane distillation, show significantly lower rejection for As(III) than for As(V). In order to treat anoxic groundwater with high As(III), which is usually associated with high $\mathrm{Fe}$, a pre-oxidation step and the removal of $\mathrm{Fe}$ (oxy)hydroxide is mandatory to avoid membrane clogging. Generally, safe disposal of the occurring arsenic rich sludges and liquid waste streams pose a difficult issue.
\end{abstract}

\section{INTRODUCTION}

Membrane processes are becoming more and more attractive in drinking water treatment due to their salient features such as i) no addition of chemicals needed, ii) separation carried out in mild environmental conditions, iii) easy to up-scale. Therefore, membrane processes have been also extensively studied for arsenic removal mainly from groundwater (Figoli, et al., 2010a, 2016; Shih, 2005). However, the use of membrane technologies still suffers from main disadvantages such as i) membrane fouling and ii) safe disposal of concentrates particularly for arsenic-laden waters.

Recently, using small-scale membrane units powered by renewable energies (solar, wind) is gaining significant interest particularly for seawater desalination in remote areas and in developing countries (Ali et al., 2018). Especially solar energy is abundant in many of these countries and costs have dropped significantly in the last years worldwide. The most growth among the renewable energy technologies has been observed in solar energy. However, the real contribution of solar energy in desalination is less than $0.02 \%$ (Ali et al., 2018).

To date, small-scale renewable energy powered membrane units are mainly applied for desalination of seawater e.g. on ships, however, for arsenic removal from groundwater these have only been studied by numerous pilot trials that have however, not entered the market and remain still as field of research (Schmidt et al., 2016). The objective of this paper is to give a short review of the current research in this field.

\section{METHODS}

\subsection{Membrane processes}

Different membrane technologies are employed in arsenic removal. Among them pressure-driven processes such as microfiltration (MF), ultrafiltration (UF), nanofiltration (NF) and reverse osmosis (RO) were studied most commonly (Figoli et al., 2010a). Hereby a water solution (feed) is passed along the membrane as crossflow and a pressure gradient forces the treated water through the membrane while retaining particulates down to solutes. However, by use of MF and UF with pore sizes between 0.01 and $0.2 \mu \mathrm{m}$ dissolved species cannot be removed (Shih, 2005).

Besides pressure-driven membrane processes, also thermally and electrically driven membrane processes are used on small-scale. Membrane distillation (MD) is a thermally driven process based on vapor pressure difference maintained across a microporous hydrophobic membrane. The diffusing vapor then condenses at the permeate membrane interface. The main advantage of MD is the fact that solar heat can be directly used without employing high pressure pumps (Manna and Pal, 2016).

In the electrodialysis (ED) process, an electrical potential difference is used as the driving force to transport the dissolved ions through ion exchange membranes. Hereby, cation and anion exchange membranes are placed alternatingly between the anode and cathode. Finally, when a salt containing feed solution is fed to the electrodialysis unit one cell of the pair becomes depleted of ions while the adjacent cell becomes enriched in ions. The salient feature of ED 
is that only low-pressure pumps and no high-pressure pumps as for RO are needed.

A relatively new membrane process for water treatment that has been studied on laboratory scale for arsenic removal is forward osmosis (FO). The principle of FO process relies on using the natural osmotic process to draw water across a semipermeable membrane from a saline feed water to a higher concentrated solution, namely the draw solution (DS). The driving force is therefore created naturally by the difference in osmotic pressure between the DS and the feed solution (FS). This offers several advantages over conventional hydraulic pressure-driven membrane processes (e.g. RO) such as lower energy requirements and reduced membrane fouling potential (McCutcheon and Elimelech, 2006). However, regarding drinking water production it should be pointed out that due to the fact that water is always drawn into a saline DS an additional separation step to recover the water from the DS is needed.

\subsection{Arsenic speciation}

The most dominant forms of arsenic in the environment are the pentavalent arsenate $\mathrm{As}(\mathrm{V})$ and trivalent arsenite $\mathrm{As}$ (III). Redox and $\mathrm{pH}$ conditions of the water control the speciation of As (Sharma and Sohn, 2009). Typical As(V) species being present under oxidizing aerobic conditions are the mono- and divalent oxyanionic forms $\mathrm{H}_{2} \mathrm{AsO}_{4}^{-}$and $\mathrm{HAsO}_{4}^{2-}$, respectively, while the neutral $\mathrm{As}$ (III) species $\mathrm{H}_{3} \mathrm{AsO}_{3}$ exists in anaerobic groundwater of $\mathrm{pH}$ lower than 9 (Camacho et al., 2011). Arsenic desorption under oxidizing conditions and high $\mathrm{pH}$ explains the high $\mathrm{As}(\mathrm{V})$ concentrations in the groundwater of extended areas of the ChacoPampean plain in Argentine and its continuation into the adjacent plains of Uruguay (Bundschuh et al., 2010). In West Bengal (India), Bangladesh down to South East Asia (Cambodia, Vietnam) the groundwater is typically anoxic and arsenite As(III) predominates (Kar et al., 2010). In this region high arsenic concentration is typically associated with high dissolved $\mathrm{Fe}$ and Mn (Kar et al., 2010).

As a matter of fact, the toxicity and the removability of arsenic differ between As(III) and As(V). As(III) is considered to be more toxic and generally more difficult to remove from water than As(V) (USEPA, 2001). The WHO recommended maximum contaminant level (MCL) of total As is set at $10 \mu \mathrm{g} \mathrm{L}^{-1}$.

\section{RESULTS AND DISCUSSION}

\subsection{Nanofiltration}

Experimental studies have shown that NF membranes cannot significantly reject arsenite at neutral and lower $\mathrm{pH}$ (Uddin et al., 2007). This can be explained by the fact that NF process is strongly dependent on charge exclusion effects caused by interaction of the charged membrane and the charged species such as arsenate whereas arsenite is neutral in charge (see 2.2). Uddin et al. (2007) compared the performance of the "loose", Dow NF200 with the "dense" Dow NF90 in the range of $100-1000 \mu \mathrm{g} \mathrm{L}^{-1}$ by use of synthetic water. Arsenic rejection of the NF90 was always significantly higher than for the NF200. The NF90 achieved highest rejection for arsenate ( $>98 \%$ ) and was able to comply with the MCL of $10 \mu \mathrm{gL}^{-1}$ for up to $1000 \mu \mathrm{g} \mathrm{L}^{-1}$ feed concentrations $\left(10\right.$ bar, $\left.\mathrm{pH} 7.3,25^{\circ} \mathrm{C}\right)$. However, the removal of arsenite under the same conditions was only $53-59 \%$ and hence the MCL could not be achieved in the entire feed range.

Figoli et al. (2010b) studied the influence of operating parameters on the removal of pentavalent $\mathrm{As}(\mathrm{V})$ from synthetic water by use of the Dow NF90 and the Microdyn-Nadir N30F. The As rejection of the "dense" NF90 was significantly higher (>91\%) than for the "loose" N30F.

\subsection{Reverse osmosis}

Many studies were conducted regarding arsenic removal by RO (e.g. Geucke et al., 2009; Schmidt et al., 2016). It has been shown that rejection of arsenate is at least as efficient as for the dense NF, however, As(III) rejection is only slightly better. Geucke et al. (2009) studied the performance of the Dow XLE, Dow TW30 and Dow SW30 in a small-scale RO desalinator. They showed that for trivalent arsenic the arsenic values in permeate could be kept below the MCL of $10 \mu \mathrm{g} \mathrm{L}^{-1}$ only up to a feed concentration of approximately $350 \mu \mathrm{g} \mathrm{L}^{-1}$. As (V) was rejected efficiently up to a feed concentration higher than $2000 \mu \mathrm{g} \mathrm{L}^{-1}$, without crossing the MCL level in permeate. As for the NF process, this fact can be explained by a charge exclusion effect.

Schmidt et al. (2016) conducted pilot trials at two sites namely Bind Toli and Ramnagar near Patna, Bihar, India with a small technical RO desalinator. The arsenic in feed was 480 and $67 \mu \mathrm{g} \mathrm{L}^{-1}$, respectively. The total arsenic reduction on both grounds was around 99\% and in most of the cases the arsenic concentration in permeate was in compliance with the National Indian Standard of $10 \mu \mathrm{g} \mathrm{L}^{-1}$. In order to avoid clogging of the membrane they conducted an upfront oxidation by air and granular media filtration (sand, anthracite) step. Hereby the majority of dissolved iron was removed as iron(oxy)hydroxide $(\mathrm{Fe}(\mathrm{O}) \mathrm{OH})$. Thus, a great part of arsenic could be also removed by coprecipitation and filtration, so that the RO unit served only as polisher to comply with the stringent MCL of $10 \mu \mathrm{g} \mathrm{L}^{-1}$ (Schmidt et al., 2016). The RO unit made use of an energy recovery system in order to keep the energy consumption low $\left(\sim 3-4 \mathrm{Wh} \mathrm{L}^{-1}\right)$.

\subsection{Membrane distillation}

The main advantages of MD are the direct use of thermal energy (e.g. solar energy) and the high As(III) rejection that makes it attractive for application in remote areas particularly in India and Southeast Asia (Table 1). Criscuoli et al. (2013) studied 
Table 1. Overview of advantages and disadvantages of membrane technologies on arsenic removal.

\begin{tabular}{|c|c|c|c|c|}
\hline \multirow{2}{*}{$\begin{array}{l}\text { Type of } \\
\text { membrane } \\
\text { process }\end{array}$} & \multicolumn{2}{|c|}{ Removal efficiency } & \multirow[b]{2}{*}{ Advantages } & \multirow[b]{2}{*}{ Disadvantages } \\
\hline & $\mathrm{As}(\mathrm{V})$ & As(III) & & \\
\hline NF & + & - & $\begin{array}{l}\text { - Capable of removal of other groundwater } \\
\text { contaminants (salinity, micropollutants) } \\
\text { - Can be operated at low pressure (<6 bar) }\end{array}$ & Low efficiency for As(III) removal \\
\hline RO & ++ & $+/ \mathrm{o}$ & $\begin{array}{l}\text { - High removal rate of other groundwater } \\
\text { contaminants (salinity, micropollutants) }\end{array}$ & Relatively high energy consumption \\
\hline MD & ++ & ++ & $\begin{array}{l}\text { - High efficiency for As(III) removal } \\
\text { - Direct use of heat for driving the process }\end{array}$ & $\begin{array}{l}\text { Relatively low water flow per } \\
\text { unit area (flux) }\end{array}$ \\
\hline ED & + & $-/ \mathrm{o}$ & $\begin{array}{l}\text { - No need for pressure pumps } \\
\text { - Direct use of electrical energy }\end{array}$ & Low efficiency for As(III) removal \\
\hline FO & ++ & $-/ o$ & $\begin{array}{l}\text { - Low fouling propensity } \\
\text { - Double barrier due to necessity of additional } \\
\text { process for regeneration of draw solution }\end{array}$ & $\begin{array}{l}\text { Has to be operated as combined } \\
\text { process due to regeneration of } \\
\text { draw solution }\end{array}$ \\
\hline
\end{tabular}

arsenic removal by use of vacuum membrane distillation (VMD) with synthetic aqueous solutions up to $0.5 \mu \mathrm{g} \mathrm{L}^{-1} \mathrm{As}(\mathrm{III})$ and $\mathrm{As}(\mathrm{V})$, respectively. Arsenic in the produced permeate was always below the detection limit. However, permeate water flux was typically lower compared to NF or RO (Criscuoli et al., 2013). Mann and Pal (2016) used a pilot-scale flash vaporization membrane distillation (FVMD) to treat an arsenic groundwater with $396 \mu \mathrm{g} \mathrm{L}^{-1}$ As from a well in West Bengal, India. After $40 \mathrm{~h}$ long operation, flux remained almost constant at around $36 \mathrm{~kg} \mathrm{~m}^{2} \mathrm{~h}^{-1}$ while arsenic was below detection limit in the distillate sample.

\subsection{Electrodialysis}

The strength of ED is its direct use of electric energy and the necessity of only small low-pressure pumps. Gonzales et al. (2017) studied purification of brackish groundwater in northern Chile $\left(\mathrm{TDS}=5482 \mathrm{mg} \mathrm{L}^{-1}\right.$ ) with high concentration of arsenic $\left(2.04 \mathrm{mg} \mathrm{L}^{-1}\right)$ using a solar powered ED unit. The purification process partially combined the ED system with upfront ion exchange and adsorption technologies (column filtration system). The ion exchanger was operated to remove hardness and the adsorption unit was used for arsenic removal. For the untreated feed with high arsenic the removal efficiency achieved $93-94 \%$ and for the combined process $99.9 \%$ (being in compliance with MCL). The lowest specific electricity consumption was $2.16 \mathrm{kWh} \mathrm{m}^{-3}$ for the ED and $5.46 \mathrm{kWh} \mathrm{m}^{-3}$ for the combined system (Gonzales et al. 2017).

\subsection{Forward osmosis}

Mondal et al. (2014) studied arsenic removal at laboratory scale with a commercial FO membrane (provided by HTI) by use of artificial water solutions and two draw solutions (glucose, $\mathrm{MgSO}_{4}$ ). The removal efficiency was more than $98 \%$ when the initial $\mathrm{As}(\mathrm{V})$ concentration was $500 \mu \mathrm{g} \mathrm{L}^{-1}$ in a neutral $\mathrm{pH}$ range (Mondal et al., 2014). The rejection increased with increasing $\mathrm{pH}$ of the feed solution and the As concentration was below the MCL under optimized conditions. However, for As(III), a significant lower rejection was observed $(<20 \%$ at $\mathrm{pH} 7)$ and only oxidation of $\mathrm{As}(\mathrm{III})$ at neutral $\mathrm{pH}$ increased the rejection to $95.7 \%$.

Hoinkis et al. (2016) conducted laboratory trials with a commercial membrane provided by Porifera and As(III) and As(V) model solutions (As feed concentration up to $400 \mu \mathrm{g} \mathrm{L}^{-1}$ ). The experiments showed that rejection of $\mathrm{As}(\mathrm{V})$ is significantly better than of As(III). For As(III) from $50 \mu \mathrm{g} \mathrm{L}^{-1}$ in feed solution arsenic level in draw solution exceeded the MCL of $10 \mu \mathrm{g} \mathrm{L}^{-1}$. However, it should be noted that FO has to be run as combined process with e.g. RO or MD to regenerate the draw solution what serves as a second barrier and further reduces arsenic.

\subsection{Concept for As(III) removal}

As mentioned above, most of the membrane processes show low removal efficiency for As(III) and pre-oxidation is needed (e.g. by $\mathrm{H}_{2} \mathrm{O}_{2}, \mathrm{O}_{3}, \mathrm{MnO}_{2}$ ). Moreover, when treating groundwater in the developing regions like India and Southeast Asia in many cases oxidation is required as pre-treatment since As(III) in the typically anoxic water is commonly associated with high $\mathrm{Fe}$ and $\mathrm{Mn}$. When $\mathrm{Fe}$ is oxidized it forms sparingly soluble $\mathrm{Fe}(\mathrm{O}) \mathrm{OH}$ which needs to be separated by filtration otherwise severe membrane clogging may occur also for MD which is basically able to remove trivalent arsenite. Due to co-precipitation this $\mathrm{Fe}($ oxy)hydroxide sludge also contains high arsenic level and it is consequently difficult to dispose it safely. An interesting option of waste-free pre-treatment is offered by subsurface arsenic remediation by aeration (van Halem, 2010).

In order to comply with the stringent MCL subsequently to the oxidation step NF or MD can be employed. NF is a simple and robust treatment, which can be operated at lower pressure compared to RO, and MD can make direct use of solar heat. 


\section{CONCLUSIONS}

Existing membrane technologies such as NF, RO, $\mathrm{ED}$ and MD offer promising opportunities to treat arsenic-laden groundwater by renewable energy in developing countries. Their advantages are the simplicity of the technology and the scalability down to very-small modules. However, in order to treat anoxic groundwater with high As(III), which is usually associated with high $\mathrm{Fe}$, pre-oxidation and removal of $\mathrm{Fe}$ (oxy)hydroxide is mandatory. The safe disposal of the occurring arsenic rich sludges pose still a difficult issue.

\section{REFERENCES}

Ali, A., Tufa, R.A., Macedonio, F., Curcio, E. \& Drioli, E. 2018. Membrane technology in renewable energy driven desalination. Renew. Sust. Energy. Rev. 81: 1-21.

Bundschuh, J., Litter, M., Ciminelli, V.S.T., Morgada, M.E., Cornejo, L., Hoyos, S.G., Hoinkis, J., Alarcon-Herrera, M.T., Armienta, M.A. \& Bhattacharya, P. 2010. Emerging mitigation needs and sustainable options for solving the arsenic problems of rural and isolated urban areas in Latin America - a critical analysis. Water Res. 44(19): 58285845.

Camacho, L.M., Gutierrez, M., Alarcon-Herrera, M.T., de Lourdes Villaba, M. \& Deng, S. 2011. Occurrence and treatment of arsenic in groundwater and soil in northern Mexico and southwestern USA. Chemosphere 83(3): 211-225.

Criscuoli, A., Bafaro, P. \& Drioli, E. 2013. Vacuum membrane distillation for purifying waters containing arsenic. Desalination 323: 17-21.

Figoli, A., Criscuoli, A. \& Hoinkis, J. 2010a. Review of membrane processes for arsenic removal from drinking water. In: N. Kabay, J. Bundschuh, B. Hendry, M. Bryjak, K. Yoshizuka, P. Bhattacharya \& S. Anac (eds) The Global Arsenic Problem: Challenges for safe water production. CRC Press, Boca Raton, FL, pp. 131-145.

Figoli, A., Cassano, A., Criscuoli, A., Mozumder, M.S.I., Uddin, M.T., Islam, M.A. \& Drioli, E. 2010b. Influence of operating parameters on the arsenic removal by nanofiltration. Water Res. 44(1): 97-104.

Figoli, A., Hoinkis, J. \& Bundschuh, J. (eds) 2016. Membrane Technologies for Water Treatment: Removal of Toxic Trace Elements with Emphasis on Arsenic, Fluoride and Uranium. CRC Press, Boca Raton, FL.

Gonzales, A., Grageda, M. \& Ushak, S. 2017. Assessment of pilot-scale water purification module with electrodialysis technology and solar energy. Appl. Energy 206: 16431652 .
Hoinkis, J., Jentner, J., Buccheri, S., Deowan, S.A., Figoli, A. \& Bundschuh, J. 2016. Forward osmosis - challenges and opportunities of a novel technology for arsenic removal from groundwater. Arsenic Research and Global Sustainability - As 2016: Proceedings of the 6th International Congress on Arsenic in the Environment, 19-23 June 2016, Stockholm, Sweden, pp. 523-524.

Kar, S., Maity, J.P., Jean, J.S., Liu, C.C., Nath, B., Yang, H.J. \& Bundschuh, J. 2010. Arsenic-enriched aquifers: occurrence and mobilization of arsenic in groundwater of Ganges Delta Plain, Barasat, West Bengal, India. Appl. Geochem. 25(12): 1805-1814.

Manna, A.K. \& Pal, P. 2016. Solar-driven flash vaporization membrane distillation for arsenic removal from groundwater: Experimental investigation and analysis of performance parameters. Chem. Eng. Prog. 99: 51-57.

McCutcheon, J.R. \& Elimelech, M. 2006. Influence of concentrative and dilutive internal concentration polarization on flux behavior in forward osmosis, J. Membr. Sci 284(1-2): 237-247.

Mondal, P., Hermans, N., Tran, A.T.K., Zhang, Y., Fang, Y., Wang, X. \& Van der Bruggen, B. 2014. Effect of physicochemical parameters on inorganic arsenic removal from aqueous solution using a forward osmosis membrane. $J$. Environ. Chem. Eng. 2(3): 1309-1316.

Schmidt, S.A., Gukelberger, E., Hermann, M., Fiedler, F. Großmann, B., Hoinkis, J., Ghosh, A., Chatterjee, D. \& Bundschuh, J. 2016. Pilot study on arsenic removal from groundwater using a small-scale reverse osmosis system Towards sustainable drinking water production. J. Hazard. Mater. 318: 671-678.

Sharma, V.K. \& Sohn, M. 2009. Aquatic arsenic: toxicity, speciation, transformation and remediation. Environ. Int. 35(4): 743-759.

Shih, M.C. 2005. An overview of arsenic removal by pressuredriven membrane processes. Desalination 172. 85-97.

Uddin, M.T. Mozumder, M.S.I. Islam, M.A., Deowan, S.A. \& Hoinkis, J. 2007. Nanofiltration membrane process for the removal of arsenic from drinking water. Chem. Eng. Technol. 30(9): 1248-1254.

USEPA 2001. National Primary Drinking Water Regulations: Arsenic and Clarifications to Compliance and New Source Contaminants Monitoring.

Van Halem, D., Heijman, S.G.J., Johnston, R., Huq, I.M., Ghosh, S.K., Verberk, J.Q.J.C., Amy, G.L. \& Van Dijk, J.C. 2010. Subsurface iron and arsenic removal: low-cost technology for community-based water supply in Bangladesh. Water Sci. Technol. 62(11): 2702-2709. 